\title{
A Survey of Conceptualizations of Politeness
}

\author{
Lei Qiu ${ }^{1 \& 2}$ \\ ${ }^{1}$ Lecturer of School of Foreign Languages, Huaiyin Normal University, Huai' an, China \\ ${ }^{2} \mathrm{PhD}$ student of Graduate School of International Cultural Studies, Tohoku University, Sendai, Japan \\ Correspondence: Qiu Lei, School of Foreign Languages, Huaiyin Normal University, 111\# Changjiang West \\ Road, Huai'an, Jiansu Province, China. Tel: 86-0517-8352-5505. E-mail: connieqiulei@163.com
}

Received: September 21, 2015 Accepted: October 10, 2015 Online Published: November 30, 2015

doi:10.5539/ijel.v5n6p115 URL: http://dx.doi.org/10.5539/ijel.v5n6p115

\begin{abstract}
Along with the general trends of research from traditional Gricean approach to postmodern approach, politeness has been conceptualized as facework, social indexing concept, relational work and interactional work. Based on examination of debates over East group-oriented and Western individual-oriented politeness, first-order and second-order politeness, as well as the universality and relativity of conceptualizations, this paper has roughly demonstrated that the tension between universality and relativity of politeness can help to explain the reason for lack of uniform definition and concept in this field. It is essential for researchers to seek a universal second-order culture-general theoretical construct on one hand, and to look at first-order culture-specific constructs on the other hand.
\end{abstract}

Keywords: politeness, conceptualization, universality, relativity

\section{Introduction}

In daily life, it is often very easy for us to make judgments of what is polite and what is not polite. For example, to hold the elevator door open for an elderly or a disabled people is considered polite behavior, to interrupt when someone is talking is considered impolite. Even for verbal communication, native speakers seem to have certain intuition to work out how to interact with others politely and how to judge whether someone's words are polite or not. However the questions of what indeed politeness is, and what mechanism or criterion people use to make those judgments are fascinating and tricky for scholars, and they are by no means easy to answer. This paper will make a general survey of the conceptualizations of politeness emerging along with the developments of politeness research so as to promote our understanding of research in this field.

\section{Origin of Theoretical Research on Politeness}

The research of politeness arises along with the debate over the meaning conveyed in language. Traditionally, formalists treat declarative sentences as 'statement' with truth values, i.e., sentences must be either true or false (Russel, 1940). With his enlightening book how to do thing with words, Austin (1962) is the first one to point out that in making an utterance, a speaker also performs certain actions or does things with words. This view is thought to be a breakthrough in linguistics, since "it points out that many everyday language declarative sentences are not intended to make true or false statements, as is firmly asserted by logical positivists. Rather, they are used to 'do things', that is, to perform certain linguistic actions such as requesting, complimenting, apologizing, and so on" (Nguyen, 2005, p. 34).

Searle (1975) further developed and extended Austin's theory by proposing the notion of indirect speech act in which "the speaker communicates to the hearer more than he actually says by way of relying on their mutually shared background information, both linguistic and nonlinguistic, together with the general powers of rationality and inference on the part of the hearer" (1975, pp. 60-61). Grice (1975) also pointed out that rational verbal communication of human being is characterized as observing a general underlying cooperative principle, namely, as he said "make your conversational contribution such as is required, at the stage at which it occurs, by the accepted purpose or direction of the talk exchange in which you are engaged." (1975, p. 45) According to Grice, the general supposition held by conversation participants is that people generally observe the cooperative principle and its four maxims can generate conversational implicature. What's more, both Searle and Grice mentioned that politeness can be a chief factor which affects participants' varied choices of language forms. Since then, their observations have inspired numerous researchers to explore the nature of politeness and its 
function in determining people's ways of conversation.

\section{Conceptualizations of Politeness}

Having a quick look at the literature on politeness, one can easily find tremendous confusion and a lack of general consensus regarding its definition and conceptualization. Although lots of attempts have been made to incorporate findings into the existing theoretical frameworks of politeness, there is still no agreement and unifying framework in the field. Along with the general trends of research from traditional Gricean approach to postmodern approach, politeness has been conceptualized as facework, social indexing concept, relational work and interactional work.

\subsection{Politeness as Facework}

The most influential politeness model to date is the one put forward by Brown and Levinson (1987). Adopted and developed from Goffman (1967) and fundamental to their theory, the notion of face refers to "the public self-image that every member wants to claim for himself..." (Brown \& Levinson, 1987, p. 61). Based on the definition, Brown and Levinson distinguished between 'positive face' and 'negative face'. Positive face is one's desire to be approved, accepted, and valued by others; whereas negative face is the desire to be free from imposition from others. In social interaction, each interactant is obliged to protect both his/her own face and that of other interactant(s). However, according to Brown and Levinson nearly all speech acts are face-threatening acts (FTAs), which intrinsically infringe on the interlocutor's face. Consequently, politeness strategies are involved in redressing those face threatening acts.

As each speaker is endowed with rationality, the crucial assumption is that the speaker will choose the best possible strategy before performing an FTA. Brown and Levinson (1987) outline four strategies speakers can use in performing a face threatening act, arranging them hierarchically based on the degree to which they threaten the hearer's face. The most threatening strategy is performing the FTA bald on record and the least threatening linguistic strategy is performing the FTA off record. Falling in between these two extremes are strategies of doing FTAs on record but with redressive action: positive politeness strategies or negative politeness strategies. Positive politeness strategies emphasize solidarity with the hearer, while negative politeness strategies emphasize distance by accommodating the hearer's right to freedom from imposition. Negative politeness is regarded less threatening than positive politeness since the latter is based on the assumption of closeness between speaker and hearer. In addition, Brown and Levinson claim that although the content of face differs in various cultures, the knowledge of members' public self-image or face, and the social necessity to orient oneself to it in interaction, are universal (1987).

\subsection{Politeness as a Social Indexing Concept}

Researchers working with Japanese language challenge Brown and Levinson's model of politeness, stating that it does not adequately account for the social-indexing aspect of politeness and it represents a Western-biased account of politeness phenomena. Based on her observation of linguistic politeness in Japanese, for example, honorific language, Ide (1989) claimed that another aspect of politeness termed as "discernment" (p. 230) had been neglected in Brown and Levinson's frame work. She regarded the neglected aspect as the speaker's use of politeness expressions, usually formal linguistic forms, "to conform to the expected and/or prescribed norms of speech appropriate to the contextual situation in individual speech communities" (Ide, 1989, p. 225). Corresponding to Japanese concept wakimae, polite behavior of this kind means that an individual has "to show verbally and non-verbally one's sense of place or role in a given situation according to social conventions" (Ide, 1989, p. 230). Different from Brown and Levison's volitional politeness strategies, which are face-wants oriented, discernment politeness is oriented mainly toward "the wants to acknowledge the ascribed positions or roles of participants as well as to accommodate to the prescribed norms of the formality of particular settings" (Ide, 1989, p. 231). What's more, in Japanese culture, the individual is more concerned with abiding by those prescribed norms of behavior, rather than with maximizing benefits to the self and his/her face. In such a culture, parameters of Japanese politeness is fixed, mandatory and consisting largely of intergroup constraints on speech which are independent of the speakers individual rational intentions, and thus discernment rather than face is the motivating force behind politeness. Therefore, the use of expressions of politeness in Japanese involves speakers' acknowledgment of status difference and their accommodation to social conventions, and politeness thus is mainly a social indexing concept.

\subsection{Politeness as Relational Work}

By making a distinction between first order and second order politeness, Locker and Watts (2005) regard politeness as a discursive concept and only part of their relational work. According to them, first order politeness 
is a commonsense or lay notion of politeness which represents how participants in verbal interaction make explicit use of the terms "polite" and "politeness" to refer to their own and others' social behavior (Locker \& Watts, 2005), whereas second order politeness is a theoretical, linguistic notion in a sociolinguistic theory of politeness. Based on this distinction, they believe that the second-order top-down evaluation of verbal and non-verbal behavior as inherently polite or impolite is inaccurate, and instead, this evaluation must be subject to the interlocutors' interpretation of a given context, that is, it is first-order interpretation that should be taken into count in politeness research. Criticizing that Brown and Levinson's research tradition only deals with mitigation of face-threatening acts and not politeness, Locher and Watts (2005) treat facework from a new perspective, namely relational work, by extending the research scope from "direct, impolite, rude or aggressive interaction through to polite interaction, encompassing both appropriate and inappropriate forms of social behavior" (Locher, 2004, p. 51). They also further introduce the lay interpretation of polite behavior as politic/appropriate behavior verbal or non-verbal in any social interaction, and add polite behavior as the surplus of politic behavior, but both politic and non-politic behaviors are included in relational work. There are no discrete divisions as unmarked politic behavior and positively marked behavior, since they are of the same nature and there is the possibility of overlapping in particular context as well. Relational work reflects the idea that depending on social and contextual variables the interpretation of polite and impolite behavior is different from culture to culture.

\subsection{Politeness as Interactional Work}

Interactional approach can be roughly considered as a development based on the combination of second-order theoretical approach and discursive approach. Instead of rejecting universal theoretical construct like postmodern approach, interactional approach tries to provide a sociological account for politeness by using a technical, second-order conception of politeness.

Scholars such as Arundale (2010), Terkourafi (2005), and Grainger (2011) who tried to take the best of first and second order politeness research have just adopted this approach. In his research, Arundale (2010) treats face as "participants' interpretings of relational connectedness and separateness, conjointly co-constituted in talk/conduct in interaction" (Arundale, 2010, p. 2078). His face constituting theory explains face and facework as achieved by participants engaged in face-to-face communication in situated relationships. According to Arundale, although separated as two different processes in interaction, both "meaning", "action" and face are achieved in a non-summative and reciprocal way. For "meaning" and "action", participants assign "provisional" interpretings to how others interpret their behavior and to the behavior of others. Participants assess others' behavior and make use of evidence in subsequent interaction to either confirm or revise "provisional" meaning, and finally arrive at "operative" interpretings. For face, in the same manner, by seeking evidence in subsequent interaction participants arrive at operative interpretings regarding face. They then evaluate the appropriate expression of face against their understanding of their relationship with others and the current context. Finally they compare their understanding with their perception of face as projected by others to interpret others' behavior as "threat" "stasis" or "support" of face in interaction.

Accounting for language-in-interaction by using a technical, second-order conception of politeness, the interactional approach enables the analyst to offer an empirically observable interpretation of negotiated meaning without referring to participants' post-hoc evaluations of the encounter. Since analyst justifies his/her interpretation by focusing on what participants themselves make relevant in talk, the first-order meaning construction can be retained without reducing the analysis of politeness to a discussion of lay interpretations.

\section{Assessment of Varied Conceptualizations of Politeness}

\subsection{Eastern Group-Oriented Politeness vs. Western Individual-Oriented Politeness}

Brown and Levinson's politeness theory has inspired much cross-cultural and cross-linguistic contrastive pragmatic research, yet it has also provoked the argument of East-West divide in politeness. By making a distinction between discernment and volitional politeness, Ide (1989) criticized the universality of Brown and Levinson's framework and argued that in Japanese culture it is discernment politeness indicating group membership and role structures that characterizes the use of expressions of politeness. Ide (1989) in particular examined the theoretical assumptions of "face" and "rationality" in Brown and Levinson's framework. She pointed out that for a non-westerner "the weight of face itself" (p. 241) rather than "the content of face" (p. 241) matters in social interactions. She explained that in a western society with individualism as the basis for interaction, face is regarded as the key to interaction, whereas in a society with group membership as the basis for interaction, the role or status defined in a particular situation is the fundamental to interaction. She also argued that irrespective of speaker's rationality, the other key property characterizing Brown and Levinson's Model Person, "the use of honorifics can be simply socio-pragmatic concord, which operates just as 
automatically as grammatical concord" (Ide, 1989, p. 242). Based on the above observation, Ide views the framework based on face and rationality as looking at supposed universal phenomena of linguistic politeness with only one Western eye biased by individualism, whereas associated mainly with proper behavior in a social organization, linguistic politeness seen through a non-Western eye is looking with another single eye (Ide, 1989).

Assuming Western and non-Western politeness as two extremes, Ide in fact is implying an East-West divide in politeness. Following her, such Chinese scholars as Gu (1990) Mao (1994) also voiced similar claims by stating that Chinese concept of face, lian and mianzi, i.e. the "reputable, respectable images that individuals can claim for themselves from communities in which they interact, or to which they belong" (Mao, 1994, p. 457) is different from that of Western cultures, with importance attached to one's commitment to and acceptance by the group.

However, whether there is indeed an East-West divide in politeness is questioned by some other scholars. (e.g., Kasper, 1990; O' Driscoll, 1996; De Kadt, 1998). Leech (2005) refuted the East-West divide stating that collective, group culture and individualist, egalitarian culture are not absolutes: they are positions on a scale. "All politeness communication implies that the speaker is taking account of both individual and group values. In the East, the group values are more powerful, whereas in the West, individual values are" (Leech, 2005, p. 6).

The empirical study carried out by Long (2010) also shed light on our understanding of East-West divide in politeness. He investigated the use of apology expressions in gratitude situation in Japanese and found that use of apology-gratitude expressions marks an act as falling outside the boundaries of interlocutor role-relations. Although scholars (Ide, 1998; Kumatoridani, 1999) argued that apology-gratitude is used to signal formal or public discourses and is a form of deference politeness, Long's interpretation views apology-gratitude expressions as a general strategy for negotiating interlocutor role-relations. This challenged the belief that honorifics and other politeness markers in Japanese are determined by situational factors, essentially mandatory in nature, and thus unrelated to face negotiation. Long further stated that the finding of his study also provided evidence that "linguistic phenomenon which appears highly 'deterministic' can in fact be eloquently explained in terms of a process of negotiation between multiple factors. In this sense, the current account is compatible with Brown and Levison's theory and offers indirect support of its applicability to other seemingly deterministic linguistic phenomena." (p. 1074)

\subsection{Commonsense Politeness vs. Theoretical Politeness}

The distinction between commonsense and theoretical politeness dates back to the debate in the field of linguistics between proponents of truth conditional semantics and proponents of pragmatics. Taking objectivist ontological position and positivist epistemology, the former believes reality or truth exists independent of the perceiver, whereas taking subjectivist view, the latter assumes that reality can only exist in relation to observers' perception. In the field of politeness research, following Gricean cooperative principle, Brown and Levinson take politeness as face-threatening mitigation by assuming nearly all speech acts are face-threatening. In fact, they take a priori relationship between speech acts and their nature as polite or impolite, which is a positivist view and is radically rejected by postmodern views of politeness. As representatives of postmodern approach, Locker and Watts believe that the study of politeness should focus on what it means to participants to be polite. This emphasis on participant interpretations and evaluations of politeness is actually a subjectivist view, which leads them to make a distinction between first-order and second-order politeness and to argue that:

We consider it important to take native speaker assessments of politeness seriously and to make them the basis of a discursive, data-driven, bottom-up approach to politeness. The discursive dispute over such terms in instances of social practice should represent the locus of attention for politeness research.

(Locher \& Watts, 2005, p. 16)

To put it in another way, Locher and Watts are emphasizing that there is no place for second order, technical notion of politeness in politeness research, as this represents analysts' interpretation rather than participants'. Instead they focus on the hearer's perception of what is and is not polite in naturally-occurring interactions and indeed just because of their emphasis on situated, naturally occurring discourse data, postmodern approach has achieved much currency in politeness research.

It is undeniable that politeness theory and face theory should not be equated. Politeness as a commonsense term is a value-laden, disputable notion, and these properties are not adequately captured by Brown and Levinson's face theory, which claims that politeness is mitigation of various kinds of face-threatening acts.

However, to reject second order politeness and adopt this radically new account of linguistic politeness is not without problem. First, since according to Locker and Watts, linguistic politeness can only be judged by "how 
participants make explicit use of the term 'polite' and 'politeness' to refer to their own and others' social behavior" (Locker \& Watts, 2005, p. 15) and politeness is extremely variable, disputable notion among lay members of society, then without an independent definition, it is hard to circumscribe the concept of first order politeness, and it "runs the danger of becoming an exercise in the lexical semantics of the lexeme 'politeness', rather than in any way enhancing our knowledge about the phenomena we wish to study" (Terkourafi, 2005, p. 242). Second, the assessment of first order politeness can only be achieved by asking participants for post-hoc evaluations. Participants become the analyst of their own interactions and "to discover empirical regularities, one necessarily substitutes the participants' interpretation of what is going on by the interpretation of analyst." (Terkourafi, 2005, p. 244) This in fact undermines the validity of the interpretation as capturing participants' own perceptions. Third, although different from second-order, speakers' intention-oriented politeness, first-order politeness is hearers' perception-oriented, both of them rely on such psychological concepts as "intention" "perception" "evaluation" to analyze linguistic politeness. Thus assuming the encoding/decoding models of communication involving two separate systems, i.e., "an independent encoder whose output becomes the input for an independent decoder." (Arundale, 2010, p. 2079), both of them fail to capture the "on-going, conjoint co-constituting" nature of interaction in their interpretation of linguistic politeness" (Arundale, 2010, p. 2079).

\subsection{Universality vs. Relativity}

When reviewing previous theories and approaches, it is easy for us to notice that politeness research always treads a fine line in the search for a balance between universality and relativity. No matter what kind of conceptualization we consider, for example, the concept of face, the distinction between first-order and second-order politeness, it is hard to reach a unified definition of politeness due to the constant tension between its universality and relativity.

The traditional, second order, universal underlying concept of face and the radical, first order, particularized discursive concept of politeness virtually correspond to the two extremes of universality and relativity respectively. On one hand, we of course cannot accept the universality proposed by traditional approach, since it ignores the contextual/situational specificity and insists a priori relationship between linguistic forms and politeness expressions, whereas we cannot take the extreme position of postmodern approach to "abandon...any attempts to develop a universal, cross-cultural valid theory of politeness altogether" either (Haugh, 2007, p. 297). Indeed, there are scholars who tried to reconcile the two extremes. Endeavors falling into this scope are Terkourafi's (2005) framed-based view, Arundale's (2010) face constituting theory and Long's (2016) social cognitive account of relational work.

In Long's (2016) study, he pointed out mismatched conceptual equivalence between universal theoretical construct based on first order politeness and universal accounts for posting a priori relationship between linguistic forms and expressions of politeness, and reconsidered the universal conceptualizations of politeness so as to put forward an effective and universal theoretical account for postmodern theories. He identified the dual nature of cognitive salience by making distinction between "correlative salience" and "contrastive salience", and viewed the relational work as the general process for interlocutors to negotiate their role-relations as falling within or outside their expectation. In this way, he came up with a universal second-order account of relational work based on first-order interpretation with the help of underlying cognitive mechanism.

However, as Long argued that although his model provides an account for "relational work" and not "politeness", the study of culture-specific politeness is significant, since culture-specific constructs should always be the basis for the application of culture-general second-order construct. On the other hand, in the search for universality it is natural for universal principles to be absent at level of culture-specific observable phenomena, since the fundamental goal of universality is the "transcendence of variation" (Janney \& Arndt, 1993, p. 25). Therefore, it should be noted that both absolute universalist position and completely relativist position are untenable, and in cross-cultural research whether the evidence is based on the same level of abstraction also needs to be taken into account.

\section{Conclusion}

The paper has briefly reviewed varied conceptualizations of politeness by tracing the origin of theoretical research on politeness and by analyzing the features of various conceptualizations which emerged along with the general trends and developments in politeness theory. Based on examination of the debate over East group-oriented and Western individual-oriented politeness, the distinction between first-order and second-order politeness as well as the universality and relativity of conceptualizations, it has roughly demonstrated that the tension between its universality and relativity can help to explain the reason for lack of uniform definition and concept in this field. Therefore, it is essential for researchers to seek a universal second-order culture-general 
theoretical construct on one hand, and to look at first-order culture-specific constructs on the other hand. Only by bearing both sides in mind can further research avoid looking at politeness phenomena "with only one eye" (Ide, 1989, p. 243) and contribute to our understanding of this fascinating field.

\section{References}

Arundale, R. B. (2010). Constituting face in conversation: Face, facework, and interactional achievement. Journal of Pragmatics, 42, 2078-2015. http://dx.doi.org/10.1016/j.pragma.2009.12.021

Austin, J. L. (1962). How to Do Things with Words: the William James Lectures Delivered at Harvard University in 1995. Oxford: Clarendon Press.

Brown, P., \& Levison, S. C. (1987). Politeness. Some Universals in Language Usage. Cambridge: Cambridge University Press.

de Kadt, E. (1998). The concept of face and its applicability in the Zulu language. Journal of Pragmatics, 29 , 173-191. http://dx.doi.org/10.1016/S0378-2166(97)00021-0

Goffman, E. (1967). Interactional ritual: Essays on face to face behaviour. New York: Anchor Books.

Grainger, K. (2011). 'First order' and 'second order' politeness: Institutional and intercultural contexts. In Linguistic Politeness Research Group (Ed.), Discursive Approaches to Politeness (pp. 167-188). Germany: Mouton de Gruyter.

Grice, H. P. (1975). Logic and conversation. In P. Cole \& J. L. Morgan (Eds.), Syntax and Semantics 3: Speech Acts (pp. 41-58). New York: Academic Press.

Gu, Y. (1990). Politeness phenomena in modern Chinese. Journal of Pragmatics, 14, 237-257. http://dx.doi.org/10.1016/0378-2166(90)90082-O

Haugh, M. (2007). The discursive challenge to politeness research: An interational alternative. Journal of Politeness Research, 3, 295-317. http://dx.doi.org/10.1515/PR.2007.013

Ide, R. (1998). 'Sorry for your kindness': Japanese interactional ritual in pubic discourse. Journal of Pragmatics, 29, 509-529. http://dx.doi.org/10.1016/S0378-2166(98)80006-4

Ide, S. (1989). Formal forms and discernment: two neglected aspects of universals of linguistic politeness. Multilingua, 8, 223-248. http://dx.doi.org/10.1515/mult.1989.8.2-3.223

Janney, R. W., \& Arndt, H. (1993). University and relativity in cross-cultural politeness research: A historical perspective. Multilingua, 12, 13-50. http://dx.doi.org/10.1515/mult.1993.12.1.13

Kasper, G. (1990). Linguistic politeness: Current research issues. Journal of Pragmatics, 14, 193-218. http://dx.doi.org/10.1016/0378-2166(90)90080-W

Kumatoridani, T. (1999). Alternation in co-occurrence in Japanese thanks. Journal of Pragmatics 31, 623-642. http://dx.doi.org/10.1016/S0378-2166(98)00092-7

Leech, G. (2005). Politeness: Is there an East-West divide? Journal of Foreign Languages, 6, 3-29.

Locher, M. A. (2004). Power and Politeness in Action: Disagreements in Oral Communication (Vol. 12). New York: Mouton de Gruyter. http://dx.doi.org/10.1515/9783110926552

Locher, M. A., \& Watts, R. J. (2005). Politeness theory and relational work. Journal of Politeness Research, 1, 9-33. http://dx.doi.org/10.1515/jplr.2005.1.1.9

Long, C. (2010). Apology in Japanese gratitude situations: The negotiation of interlocutor role-relations. Journal of Pragmatics, 42, 1060-1075. http://dx.doi.org/10.1016/j.pragma.2009.09.005

Long, C. (2016). A social cognitive account of relational work. Journal of Politeness Research, 12(1), 1-26.

Mao, L. R. (1994). Beyond politeness theory: 'face' revisited and renewed. Journal of Pragmatics, 21, 451-486. http://dx.doi.org/10.1016/0378-2166(94)90025-6

Nguyen, M. (2005). Criticizing and responding to criticism in a foreign language: A study of Vietnamese learners of English (Doctoral dissertation). University of Auckland. Auckland, New Zealand.

O'Driscoll, J. (1996). About face: A defense and elaboration of universal dualism. Journal of Pragmatics, 25, 1-32. http://dx.doi.org/10.1016/0378-2166(94)00069-X

Russell, B. (1940). An Inquiry into Meaning and Truth. London: Allen and Unwin.

Searl, J. R. (1975). Indirect speech acts. In P. Cole \& J. L. Morgan (Eds.), Syntax and semantics (Vol. 3): Speech 
Act (pp. 59-82). New York: Academic Press.

Terkourafi, M. (2005). Beyond the micro-level in politeness research. Journal of Politeness Researh, 1, $237-262$. http://dx.doi.org/10.1515/jplr.2005.1.2.237

\section{Copyrights}

Copyright for this article is retained by the author(s), with first publication rights granted to the journal.

This is an open-access article distributed under the terms and conditions of the Creative Commons Attribution license (http://creativecommons.org/licenses/by/3.0/). 